\title{
Inoculation insensitive promoters for cell type enriched gene expression in legume roots and nodules
}

\author{
Srdjan Gavrilovic, Zhe Yan, Anna M. Jurkiewicz, Jens Stougaard and Katharina Markmann*
}

\begin{abstract}
Background: Establishment and maintenance of mutualistic plant-microbial interactions in the rhizosphere and within plant roots involve several root cell types. The processes of host-microbe recognition and infection require complex signal exchange and activation of downstream responses. These molecular events coordinate host responses across root cell layers during microbe invasion, ultimately triggering changes of root cell fates. The progression of legume root interactions with rhizobial bacteria has been addressed in numerous studies. However, tools to globally resolve the succession of molecular events in the host root at the cell type level have been lacking. To this end, we aimed to identify promoters exhibiting cell type enriched expression in roots of the model legume Lotus japonicus, as no comprehensive set of such promoters usable in legume roots is available to date.
\end{abstract}

Results: Here, we use promoter:GUS fusions to characterize promoters stemming from Arabidopsis, tomato (Lycopersicon esculentum) or L. japonicus with respect to their expression in major cell types of the L. japonicus root differentiation zone, which shows molecular and morphological responses to symbiotic bacteria and fungi. Out of 24 tested promoters, 11 showed cell type enriched activity in L. japonicus roots. Covered cell types or cell type combinations are epidermis (1), epidermis and cortex (2), cortex (1), endodermis and pericycle (2), pericycle and phloem (4), or xylem (1). Activity of these promoters in the respective cell types was stable during early stages of infection of transgenic roots with the rhizobial symbiont of L. japonicus, Mesorhizobium loti. For a subset of five promoters, expression stability was further demonstrated in whole plant transgenics as well as in active nodules.

Conclusions: 11 promoters from Arabidopsis (10) or tomato (1) with enriched activity in major L. japonicus root and nodule cell types have been identified. Root expression patterns are independent of infection with rhizobial bacteria, providing a stable read-out in the root section responsive to symbiotic bacteria. Promoters are available as cloning vectors. We expect these tools to help provide a new dimension to our understanding of signaling circuits and transcript dynamics in symbiotic interactions of legumes with microbial symbionts.

Keywords: Cell type specific expression, Cell type enriched expression, Cell type specific promoter activity, Cell type enriched promoter activity, Nodulation symbiosis, Lotus root structure, Lotus nodule structure, Lotus japonicus, Legume

\section{Background}

Plant roots are dynamic structures involved in diverse developmental and physiological processes [1]. Apart from their roles in water and nutrient homeostasis, roots perceive biotic and abiotic environmental factors from

\footnotetext{
*Correspondence: kama@mbg.au.dk

Department of Molecular Biology and Genetics, Centre for Carbohydrate

Recognition and Signalling (CARB), Aarhus University, Gustav Wieds Vej
}

10, 8000 Aarhus, Denmark the rhizosphere, and mediate appropriate responses [2-4]. Roots grow from an apical meristem at the tip and can be divided into developmental zones along their longitudinal axis [5]. The root apical meristem shows high rates of cell proliferation and is followed by the elongation zone, where meristematic activity ceases while cell elongation continues to increase cell length. Further distal from the tip, in the differentiation zone, rapid cell elongation has terminated and cells begin to acquire 
distinct cellular identities along the radial axis of the root $[4,5]$. Major cell types are the peripheral epidermis, often including both root hair-developing trichoblasts as well as atrichoblasts, the cortex including the endodermis as its innermost cell layer, the pericycle, and the central vasculature with phloem and xylem elements for rootward and shootward long-distance transport, respectively [6] (Fig. 1). These distinct cell types differentially contribute to the functionality of the organ and plant as a whole $[1,4]$. Only root cap and epidermis are in direct contact with the rhizosphere, but plant responses to stimuli also involve internal cell types such as cortex, endodermis, pericycle and vasculature [3].

The generation and maintenance of cellular identities in the root are determined by cell type dependent patterns of transcriptional activity [7-10], complemented by post-transcriptional control such as miRNA-mediated regulation of mRNA stability and translation [6]. Lee et al. [6] compared the cell type distribution of mRNAs of 44 Arabidopsis transcription factors to the respective promoter activity patterns in roots. The results suggested that for $80 \%$ of investigated genes, about three kilobases of noncoding sequence upstream of the translation start site were sufficient to reproduce mRNA abundance patterns observed by hybridization-based gene-chip analysis $[6,10]$. This observation implies that in the remaining $20 \%$, regulatory elements other than the five promoter regions contributed to mRNA patterning [6]. Beyond differential patterns of transcriptional and/or translational activity, the coordination of developmental processes requires intercellular communication and signal transduction between root cell types, in which diverse molecules including hormones [11-14], peptides [15-17] and regulatory RNAs $[17,18]$ are involved.

Many plants engage in synergistic interactions with bacterial or fungal microorganisms in their root systems. Legumes, known for their ability to form nitrogen-fixing root symbiosis, are responsive to compatible rhizobial bacteria within a section of the differentiation zone of the root referred to as the susceptible zone, that is transcriptionally distinct from other parts of the root [19]. The legume-rhizobia interaction involves the initiation of nitrogen-fixing nodule organs by the host plant, often preceded by deformation and curling of root hairs during epidermal infection [20]. In the model legume Lotus japonicus, Mesorhizobium loti bacteria usually invade the root through tube-like structures, infection threads, which initiate within root hair curls [21]. Infection progresses into and through cortical cell layers, and cortical cytokinin perception and signaling are required for reactivation of cell division [22, 23]. Within days of infection initiation, nodule primordia form in the root cortex. As their development progresses, bacteria invade the central primordial tissue through ramifying infection threads. Membrane-bound units of one or more bacteria are eventually released from infection thread tips into nodule cells, where they develop into nitrogen-fixing symbiosomes [24].

To dissect gene expression patterns in legume root interactions with microbial symbionts, previous studies

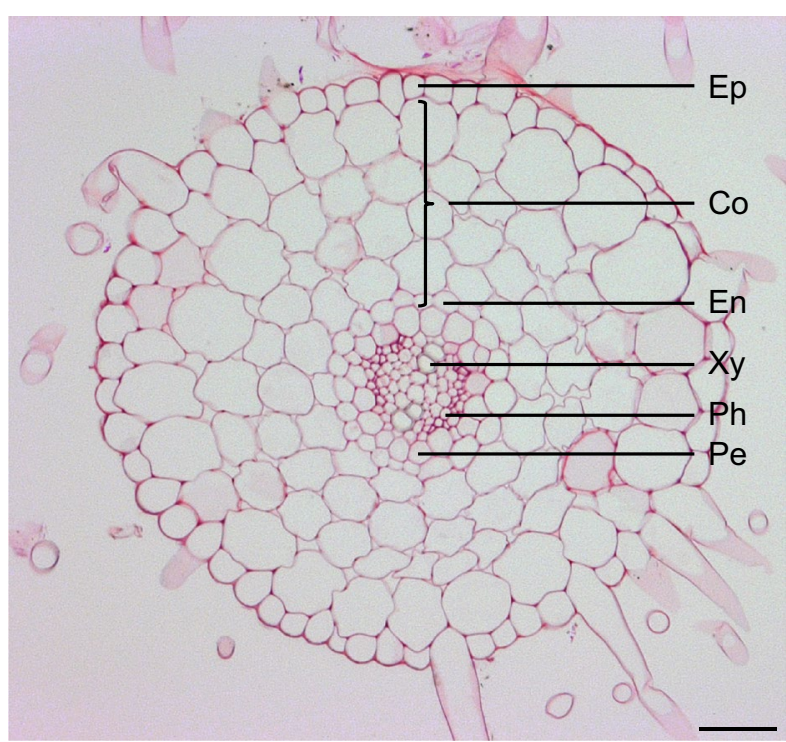

pLeExt1; pAtRSH14; pAtS31

pAtCortex; pAtRSH14; pAtS31

pAtE29; pAtE47

pAtS18

pAtS5; pAtS13; pAtS32; pAtSUC2

pAtE29; pAtS5; pAtS13

Fig. 1 Cross-section of L. japonicus root (differentiation zone). Co cortex, En endodermis, Ep epidermis, Pe pericycle, Ph phloem, Xy xylem. Names of promoters are indicated in association with the cell type(s) where promoter-GUS activity was detected in L. japonicus. Promoters are underlined to indicate the cell type of primary expression. Scale bar $50 \mu \mathrm{m}$ 
have relied on laser microdissection of defined cell pools or tissue fragments to investigate mRNA or protein populations therein [25-30]. Though specific, such approaches are elaborate, and allow for the processing of limited sample numbers only. In addition, they rely on the availability of expensive equipment.

Here, we present a set of promoters showing cell type enriched expression in one or more cell types including epidermis, cortex, endodermis, pericycle, phloem poles and xylem elements of $L$. japonicus roots. These can be used for targeted isolation of cells for global transcriptome, proteome or metabolite analysis, as well as for directed expression of genes of interest in particular cell types. Activity patterns of the promoters predominantly originating from Arabidopsis or tomato (Table 1) have been tested using GUS reporter gene fusions in transgenic roots of composite plants [31]. Infection with $M$. loti demonstrated that expression patterns were stable upon rhizobial infection at the early, pre-nodulation stage of 3 days post infection. A subset of promoter:GUS constructs was used to generate whole-plant transformants, and expression patterns in transgenic lines were confirmed to resemble those in transgenic roots of composite plants. These stable lines were further used to analyze expression activity of the respective promoters in young and mature nodules harvested at 14 days post infection. The collection of promoters established and tested here is a valuable toolbox for directing expression in particular root and nodule cell types or cell type combinations, and for global analyses of how particular cell types contribute to symbiosis and organ development in L. japonicus and related legume species.

\section{Results and discussion}

Isolation of promoters with cell type enriched expression patterns in L. japonicus roots

To identify promoters showing activity in one or more defined cell types in L. japonicus roots (Fig. 1), we

Table 1 Promoters tested for cell type enriched expression in L. japonicus roots

\begin{tabular}{|c|c|c|c|c|c|c|}
\hline $\begin{array}{l}\text { Predominant } \\
\text { expression } \\
\text { in L. japonicus roots }\end{array}$ & $\begin{array}{l}\text { Promoter } \\
\text { name }\end{array}$ & $\begin{array}{l}\text { Promoter } \\
\text { fragment } \\
\text { used (bp) }\end{array}$ & $\begin{array}{l}\text { Sequence } \\
\text { origin (species) }\end{array}$ & $\begin{array}{l}\text { Locus/ } \\
\text { accession }\end{array}$ & Gene product & References \\
\hline $\begin{array}{l}\text { Epidermis (trichoblast/ } \\
\text { atrichoblast) }\end{array}$ & pLeExt $1^{\mathrm{a}, \mathrm{b}}$ & 1122 & Tomato & NM_001247899 & $\begin{array}{l}\text { Extensin/xyloglucanv } \\
\text { endotransglycosylase }\end{array}$ & $\begin{array}{l}\text { Bucher et al. [32], } \\
\text { Mirabella et al. } \\
\text { [33] }\end{array}$ \\
\hline \multirow[t]{2}{*}{ Epidermis and cortex } & pAts31 & 3041 & Arabidopsis & At5g19790 & ERF/AP2 TF & Lee et al. [6] \\
\hline & pAtRHS14 & 1249 & Arabidopsis & At4g22080 & Pectin lyase & Won et al. [35] \\
\hline Cortex & pAtCortex ${ }^{a}$ & 1666 & Arabidopsis & At1g09750 & Aspartyl protease & $\begin{array}{l}\text { Lee et al. [6], } \\
\text { Dinneney et al. [4] }\end{array}$ \\
\hline \multirow[t]{2}{*}{ Endodermis and pericycle } & pAtE29a & 2724 & Arabidopsis & At4g05170 & bHLHTF & Lee et al. [6] \\
\hline & pAtE47 & 3296 & Arabidopsis & At2g37950 & $\mathrm{C} 3 \mathrm{HTF}$ & Lee et al. [6] \\
\hline Pericycle and phloem & pAtS5 & 2202 & Arabidopsis & At5g24800 & bZIPTF & Lee et al. [6] \\
\hline \multirow[t]{3}{*}{ Phloem and pericycle } & pAts32 & 3000 & Arabidopsis & At2g18380 & C2C2-Gata TF & Lee et al. [6] \\
\hline & pAtS13a & 4018 & Arabidopsis & At1g07640 & DofTF & Lee et al. [6] \\
\hline & pAtSUC2 ${ }^{c}$ & 942 & Arabidopsis & At1g22710 & Sucrose-proton symporter & Stadler et al. [37] \\
\hline Proto- and metaxylem & pAtS18 & 3010 & Arabidopsis & At5g12870 & MYBTF & Lee et al. [6] \\
\hline \multirow[t]{4}{*}{ Unspecific } & pLjPDC 1 & 2987 & L.japonicus & Lj1g2372300 & Pyruvate decarboxylase & This manuscript \\
\hline & pAtE30 & 3004 & Arabidopsis & At4g21340 & bHLHTF & Lee et al. [6] \\
\hline & pAtE31 & 1484 & Arabidopsis & At4g28890 & $\mathrm{C} 3 \mathrm{HTF}$ & Lee et al. [6] \\
\hline & pAtE49 & 2414 & Arabidopsis & At3g05150 & $\mathrm{C} 2 \mathrm{H} 2 \mathrm{TF}$ & Lee et al. [6] \\
\hline Unstable (phloem) & pAtso & 3082 & Arabidopsis & At5g60200 & C2C2-DofTF & Lee et al. [6] \\
\hline $\begin{array}{l}\text { Unstable (proto- and } \\
\text { metaxylem) }\end{array}$ & pAts20 & 3002 & Arabidopsis & At1g71930 & NACTF & Lee et al. [6] \\
\hline
\end{tabular}

Where promoter activity was detected in more than one cell type, the cell type of primary expression is underlined. Arabidopsis, A. thaliana; tomato, Lycopersicon esculentum; TF, transcription factor

a Available in transgenic lines expressing GUS

b For pLeExt1, expression is enhanced in trichoblasts as compared to atrichoblasts

c Expression of pAtSUC2 was exclusively seen in roots containing chloroplasts due to exposure to light

d pAtE49 shows unstable expression across most root cell types

e Expression of $p A t S 8$ is primarily associated with phloem poles, but occasional unspecific expression across root cell types is observed

f pAtS20 showed rare xylem associated expression. Where promoter activity was detected in more than one cell type, the cell type of primary expression intensity is underlined 
assembled candidates based on their published expression properties in other plant species. These were then tested for their potential to drive expression of the $E$. coli $\beta$-glucuronidase (GUS) reporter gene in L. japonicus roots in a cell type enriched manner. A total of 17 out of 24 tested promoters induced GUS activity in L. japonicus transgenic roots on composite plants (Table 1). To determine promoter activity patterns, entire transgenic roots were analyzed longitudinally. Root zones responsive to rhizobial infection, identified by the presence of immature, developing root hairs (differentiation zone), were cross-sectioned to visualize expression patterns in inner root cell types.

\section{Epidermis enriched activity}

One of the tested promoters, pLeExt1 [32, 33], showed strongly enriched activity in epidermal cells. This promoter is the upstream regulatory sequence of an extensin/xyloglucan endotransglycosylase in tomato [33]. Transgenic roots transformed with the pLeExt1:GUS reporter construct (Additional file 1: Fig. S1.1a-f) showed GUS staining in young epidermal cells just prior to or coinciding with root hair emergence (Additional file 1: Fig. S1.1a and d). Epidermal activity was equally seen in the responsive zone containing developing root hairs (Additional file 1: Fig. S1.1b, c, e and f), as well as in older root zones containing mature hairs. In contrast to the previously documented trichoblast specific activity pattern in tomato roots, pLeExt1:GUS activity was slightly enhanced in L. japonicus trichoblasts as compared to atrichoblasts, but present in both.

Root patches devoid of traceable activity were present across developmental zones. In tendency, root sections with high root hair density showed enhanced expression. In line with this, $p$ LeExt1:GUS activity in young epidermal cells depended on the pattern of root hair emergence on a particular root tip. Where root hairs developed in the vicinity of the root tip, epidermal cells tended to show GUS activity from an early and overall similar age resulting in a distinct ring of blue encircling the root tip (Additional file 1: Fig. S2), or expression activity developed more gradually (Additional file 1: Fig. S1.1a and d). Semithin cross sections of the responsive zone $(7-8 \mu \mathrm{m})$ revealed some unspecific staining in other root cell types, mainly the hypodermal layer of the cortex (Additional file 1: Fig. S1.1c and f). Promoter regions of two L. japonicus homologs of the Arabidopsis expansin gene AtExpa7, LjExpa7 and LjExpa8, have previously been shown to have strongly enriched activity in epidermal trichoblasts in L. japonicus roots [34]. Depending on the employed assortment of promoter fragments and root hair specific cis elements therein, activity was almost exclusive to root epidermal cells, or accompanied by varying levels of expression in the outer root cortex and central vasculature [34].

\section{Epidermis and cortex enriched activity}

pAtS31 [6] (Additional file 1: Fig. S1.1g-1) and pAtRHS14 [35] (Additional file 1: Fig. S1.1m-r) are promoter sequences of a pectin lyase and an ERF/AP2 (Ethylene Responsive Factor/APETALA2) transcription factor, respectively, in Arabidopsis. When coupled to a GUS reporter gene, both showed an overall similar activity pattern to pLeExt1:GUS, but apart from epidermal expression, that in cortical cells was more pronounced than observed in pLeExt1:GUS expressing roots (Additional file 1: Fig. S1.1c, f, i, l, o and r). Epidermal GUS signal was detected in both trichoblasts and atrichoblasts in roots expressing either promoter:GUS construct. In addition, pAtS31:GUS showed activity in one or more outer cortical cell layers proximal to the epidermis in all examined samples (Additional file 1: Fig. S1.1i and l), whereas pAtRHS14 activity was consistently detected in cells across the root cortex, but not in the central vascular cylinder (Additional file 1: Fig. S1.1o and r). In roots expressing either construct, patches with pronounced promoter activity alternated with patches where activity was absent.

\section{Cortex enriched activity}

pAtCortex [4, 6], driving expression of an aspartyl protease gene originally isolated from Arabidopsis and named after its cortical expression in this species, had cortex enriched activity also in L. japonicus roots when coupled to a GUS reporter (Table 1, Additional file 1: Fig. S1.2a-f). Activity predominated in the inner three to four cortical cell layers peripheral of the endodermis, but included, at a weaker level, both the innermost endodermal and outermost hypodermal layers of the cortex. Some expression was present in the epidermis and vasculature as well as pericycle (Additional file 1: Fig. S1.2c and f), but GUS levels were much lower in these cell types than in the inner root cortex. Predominance of activity in the root cortex was particularly evident from thicker $(60-80 \mu \mathrm{m})$ cross sections of the differentiation zone (Additional file 2: Fig. S3).

An additional promoter with documented cortex enriched (>90 \%) expression in Arabidopsis, pAtE49 [6], showed unspecific and unstable expression in L. japonicus roots (Table 1) and was thus not considered further.

\section{Endodermis and pericycle enriched activity}

$p A t E 29$ and $p A t E 47$ both show endodermal expression in the differentiation zone of Arabidopsis roots [6] and GUS marker gene fusions of these promoters had comparable endodermis enriched activity in L. japonicus (Additional 
file 1: Fig. S1.2g-r). GUS signal was also detected in the pericycle and, more weakly, in adjacent cells of the inner cortex of the differentiation zone (Additional file 1: Fig. S1.2i, l, o, r). In roots carrying the pAtE29:GUS construct, low signal levels were also present in more peripheral cortical layers as well as the epidermis, suggesting weak activity of the promoter in these cell types. In contrast, GUS signal was seen in endodermis, pericycle and, weakly, inner cortical cells only in pAtE47:GUS expressing roots. While an average of $62 \%$ of roots containing the pAtE29:GUS construct showed GUS expression, activity was detected in an average of $43 \%$ of roots transformed with pAtE47:GUS (Additional file 2: Table S2). This suggests less consistent activity of the latter promoter in L. japonicus roots, possibly due to a more pronounced dependence of its activation on the genomic location of the transgene.

\section{Pericycle and phloem enriched activity}

The promoter regions pAtS5, pAtS32 and pAtS13 [6] of three Arabidopsis transcription factors belonging to bZIP (Basic Leucine Zipper Domain), DOF (DNAbinding One Zinc Finger) and C2C2-GATA (containing either one or two zinc finger DNA-binding domains) families, respectively, showed pericycle and/or phloem enriched expression in L. japonicus roots. GUS signal was particularly pronounced in, but not limited to, the pericycle in pAtS5:GUS expressing roots (Additional file 1: Fig. S1.3a-f). Strong expression focused in pericycle cells opposite the phloem poles and incorporated cells of the latter. Less intense activity was apparent in pAtS5:GUS expressing pericycle cells opposing xylem poles, and occasional, weak GUS activity was present in inner cortical cells (Additional file 1: Fig. S1.3c,f). Expression of this promoter region in Arabidopsis roots similarly focused on the pericycle with about $62 \%$ of the total observed intensity, whereas just above $20 \%$ of detected expression intensity was phloem-associated [6]. A similar staining pattern, with more pronounced activity in the phloem cells but consistent, less intense GUS activity also in the associated pericycle, was observed in pAtS32:GUS expressing $L$. japonicus roots (Additional file 1: Fig. S1.3g-l). In Arabidopsis, more than $80 \%$ of the detected pAtS32 activity was phloem-associated, with very little expression present in the pericycle [6]. A similar activity pattern was detected in tomato [36].

The promoter region pAtS13 was, in line with its expression pattern in Arabidopsis roots [6], primarily active in the phloem in L. japonicus roots, with limited amounts of GUS signal detected in phloem-associated pericycle cells of pAtS13:GUS expressing roots (Additional file 1: Fig. S1.3 m-r).

Similarly, a fourth promoter tested, pAtSUC2 [37], induced GUS activity in phloem cells of pAtSUC2:GUS expressing L. japonicus roots as well as, to a lesser extent, in associated pericycle cells (Additional file 1: Fig. S4). However, expression activity was only apparent in roots that had been exposed to light and contained chloroplasts (Additional file 1: Fig. S4c-e), whereas GUS signal was entirely absent from $p A t S U C 2$ :GUS containing roots that had been shaded from light access and were photosynthetically inactive (Additional file 1: Fig. S2a-b). As root exposure to light potentially influences nodulation in both L. japonicus [38] and pea [39] we did not consider this promoter as a prime candidate. Our observations are consistent with the proposed function of $A t \mathrm{SUC} 2$, a glucoside-proton symporter [40], in phloem loading [41].

\section{Xylem enriched activity}

The activity of pAtS18, regulating the expression of AtMYB46, a member of the R2R3/MYB (containing an R2R3-type MYB DNA-binding domain) transcription factor family, was, as far as we could observe, limited to xylem elements within the central stele in L. japonicus roots (Additional file 1: Fig. S1.4a-f). Activity encompassed both proto- and metaxylem elements across the elongation and differentiation zones. This corresponds to the activity pattern observed in both Arabidopsis [6] and tomato [36]. Signal intensity was low and only detected in about $27 \%$ of transgenic roots containing the pAtS18:GUS construct (Additional file 2: Table S1).

\section{Activity patterns are stable during initial stages of rhizobial infection}

For the investigation of cell type dependent responses during early stages of infection of $L$. japonicus roots with the rhizobial symbiont $M$. loti, candidate promoters with stable, infection-independent expression patterns are favorable, as they enable the targeting of similar cell pools across treatments. We therefore analyzed expression patterns in response to infection with $M$. loti at the early stage of 3 days post infection where existent cell types are comparable and nodule organogenesis has not yet commenced. All promoters showed stable activity patterns upon M. loti inoculation as compared to mock-treatment (Additional file 1: Fig. S1), suggesting their suitability for targeted expression studies or selective isolation of cell pools during early stages of rhizobial infection. Although the average percentage of transgenic roots with detectable GUS signal varied in inoculated compared to mock treated plants for some promoters (Additional file 2: Table S1), these differences were not significant due to overall high variation levels.

Some of the tested promoters have been shown in Arabidopsis to respond to exogenous stimuli including wounding or insect attack (pAtS13) [42], or to fungal (pAtS18) [43, 44] or viral (pAtCortex) [45] pathogen 
infection. Expression stability in response to other soil microbes such as arbuscular mycorrhizal fungi, or to abiotic challenges like nutrient levels, water- or temperature regimes will be interesting aspects of further investigation to broaden the applicability of this toolset.

\section{Activity patterns are stable in transgenic plants}

A selection of promoters including pLeExt1 (epidermis), pAtCortex (cortex), pAtE29 (endodermis and pericycle), pAtS13 (phloem and pericycle), and pAtS18 (xylem) was introduced into transgenic plants to examine whether the processes of tissue culture and plant regeneration from calli influenced the observed expression patterns. Roots of three week-old seedlings homozygous for a single transgene insertion and containing up to two independent insertion sites were analyzed for GUS activity. Out of two to four independent lines tested per construct, at least one showed reproducible levels of GUS signal across root systems while maintaining a consistent cell type dependent pattern of GUS staining corresponding to what was previously observed for the respective promoter in transgenic roots (Fig. 2, Table 2, Additional file 1: Fig. S5). The remaining lines showed similar, low or no detectable promoter activity levels. For each construct, we selected one line that showed consistent GUS signal levels for further characterization (Table 2). In line with our observations in transgenic roots on composite plants, lines expressing pLeExt1:GUS (epidermis) and pAtS18:GUS (xylem) showed patchy GUS signal along roots (Additional file 1: Fig. S5a and e), whereas lines expressing $p$ AtCortex:GUS, $p A t E 29: G U S$ or $p A t A 13: G U S$ showed mostly continuous GUS signal (Additional file 1: Fig. S5b-d). Activity levels of pAtCortex:GUS were consistently more intense in younger root zones including the responsive zone, as compared to mature root sections (Additional file 1: Fig. S5b). Importantly, despite variation in overall activity levels, no lines were observed where the patterns of cell type enrichment deviated from what we observed in composite plants. This suggests that in the tested cases, promoter activity patterns were independent of whether transgenic roots on composite plants or whole plant transformants were analyzed.

\section{Nodule expression patterns}

To evaluate the suitability of the promoters for directed expression studies at later stages of nodulation symbiosis in L. japonicus, we investigated the activity patterns of pLeExt1:GUS, pAtCortex:GUS, pAtE29:GUS, pAtS13:GUS, and pAtS18:GUS in nodule cell types (Fig. 3a-c) using selected transgenic lines (Table 3). Plants were harvested at 14 days post inoculation, where the oldest nodules are mature and nitrogen fixing, but senescence has not yet set in. At this timepoint, mature and younger, immature nodules co-exist, allowing for their simultaneous analysis.

pLeExt1:GUS expressing plants showed no detectable GUS signal in nodule cells (Table 3; Fig. 4a-d). Although root epidermal cells in direct vicinity of nodules regularly showed GUS signal, signal was never detected on root hairs directly associated with nodules, independent of whether cells of the original root epidermis still persisted on emerging primordia or had been replaced by secondary external tissue (Fig. 4a, b). Compared to either non-inoculated roots or inoculated roots that had not developed nodules at the time of harvest, nodulated roots showed a reduced level of epidermal staining (Additional file 1: Fig. S6a).

Nodules on roots expressing pAtCortex:GUS showed intense GUS signal at all observed developmental stages (Table 3; Fig. 4e-h). The outer nodule cortex was free of GUS signal, a noteworthy exception being central lenticel cells flanking the vascular bundels (Fig. 4g, h). Phloem, xylem and vascular pericycle were usually unstained (Fig. 4g, h). In contrast, the vascular endodermis as the innermost cortical layer framing the vascular bundles (Fig. 3) showed weak staining in all tested nodules. This is consistent with the observed activity pattern of this promoter in the root responsive zone (Fig. 2f). GUS activity was most pronounced in the nodule parenchyma, a ring of tightly packed cortical cells surrounding the nodule centre (Fig. 3), but both infected and interstitial noninfected cells of the central nodule tissue also showed consistent staining albeit at a weaker level (Fig. 4g, h). In line with the observation that pAtCortex:GUS activity was primarily seen in young root sections including the root tip and differentiation zone, but to a lesser extent in mature root sections (Additional file 1: S5b), root sections carrying mature nodules showed low levels or no GUS staining in the root cortex (Additional file 1: Fig. S6b).

pAtE29:GUS showed consistent activity in the vascular endodermis surrounding nodule vascular bundles (Figs. 3c, 4i-l). In line with our observations in roots (Fig. 2g-i; Table 1), staining was also present in the vascular pericycle, but at a lower intensity (Fig. 4l). No GUS staining was detected in other cell types of $p A t E 29: G U S$ expressing nodules (Fig. 4k, l). Similar to pAtCortex:GUS, activity of $p A t E 29: G U S$ in roots was most prominent in younger root sections, but occasionally co-existed with the presence of mature nodules (Additional file 1: Fig. $\mathrm{S} 6 \mathrm{~b}-\mathrm{c})$.

pAtS13:GUS was active throughout the nodule parenchyma and in uninfected central cells of pAtS13:GUS expressing nodules (Fig. $4 \mathrm{~m}-\mathrm{p}$ ). Activity was already apparent in primordia but at low levels (Fig. 4m), and mature nodules showed intense GUS staining (Fig. 4n). 

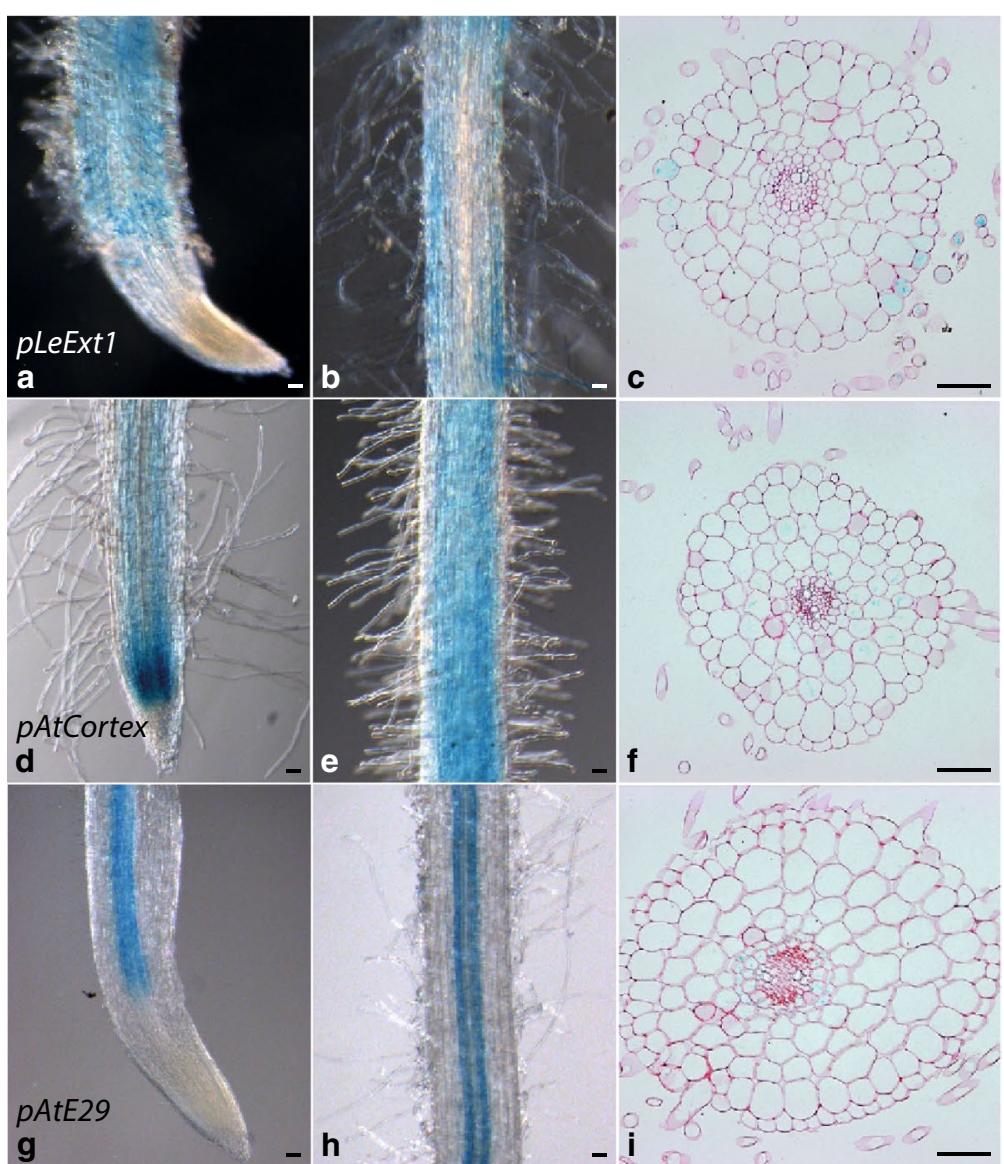

g
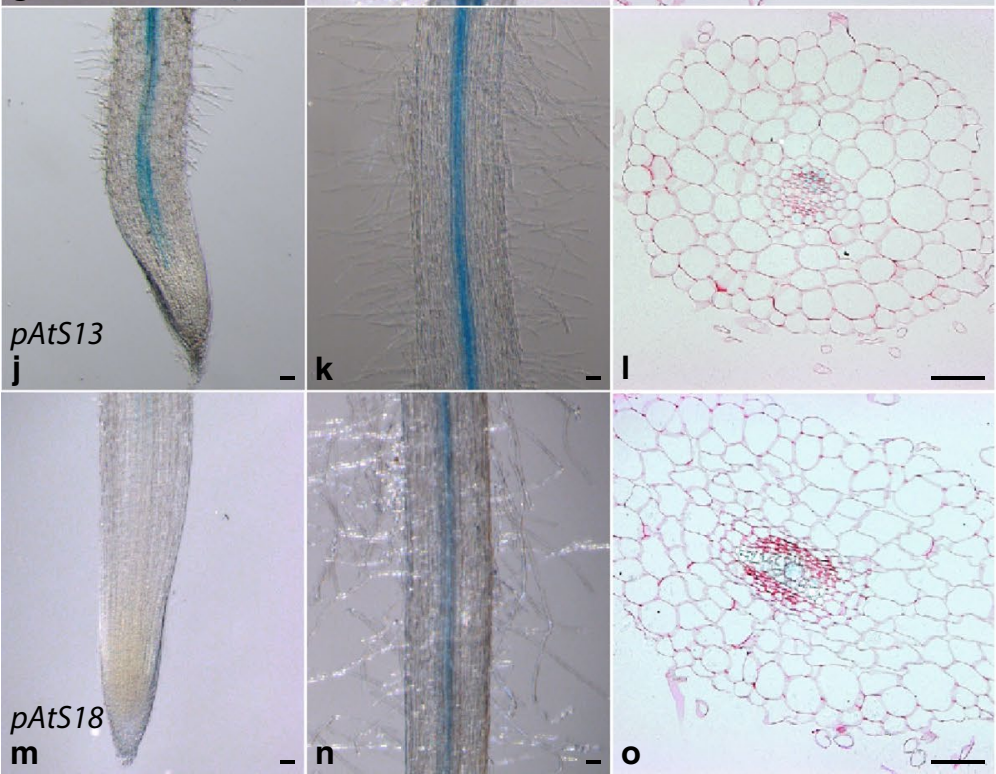

Fig. 2 Patterns of cell type enriched promoter activity as indicated by GUS staining are maintained following whole plant regeneration from calli using selected promoter:GUS constructs. Transgenes are a-c LeExt1:GUS (line LIG29-2); d-f pAtCortex:GUS (line CoG11-6); g-i pAtE29:GUS (line 29G4b-5); j-I pAtS13:GUS (line 13G26b-28) and $\mathbf{m}-\mathbf{o}$ pAtS18:GUS (line XG5A-5). Uninoculated transgenic plants were harvested 3 weeks post germination. Representative GUS stained root tips $(\mathbf{a}, \mathbf{d}, \mathbf{g}, \mathbf{j}, \mathbf{m}$ entire root mounts) and responsive zone fragments $(\mathbf{b}, \mathbf{e}, \mathbf{h}, \mathbf{k}, \mathbf{n}$ entire root mounts; $\mathbf{c}, \mathbf{f}$, $\mathbf{i}, \mathbf{I}, \mathbf{o}$ cross sections) are shown. Cross sections are $7-8 \mu \mathrm{m}$ microtome sections of resin (Kulzer Technovit 7100 ) embedded roots stained with $0.1 \%$ Ruthenium Red. Scale bars 50 um 
Table 2 Stable lines expressing selected promoter:GUS constructs

\begin{tabular}{|c|c|c|c|c|c|c|}
\hline Promoter & Line name & Replica & Total plant \# & Total GUS+ & Total GUS- & \%GUS+ \\
\hline \multirow[t]{3}{*}{ pLeExt1 } & LIG 29-2 & 3 & 18 & 18 & 0 & 100 \\
\hline & LIG31A-19 & 2 & 11 & 11 & 0 & 100 \\
\hline & LIG26-7 & 2 & 11 & 9 & 2 & 81.82 \\
\hline \multirow[t]{3}{*}{ pAtCortex } & $\underline{\operatorname{Cog} 11-6}$ & 3 & 13 & 13 & 0 & 100 \\
\hline & CoG29-1 & 2 & 10 & 10 & 0 & 100 \\
\hline & CoG5b-23 & 2 & 10 & 0 & 10 & 0 \\
\hline \multirow[t]{2}{*}{ pAtE29 } & $29 G 4 b-5$ & 3 & 15 & 15 & 0 & 100 \\
\hline & 29G7-32 & 2 & 15 & 15 & 0 & 100 \\
\hline \multirow[t]{2}{*}{ pAtS13 } & $13 G 26 b-28$ & 3 & 14 & 14 & 0 & 100 \\
\hline & $13 G 3 b-100$ & 2 & 11 & 11 & 0 & 100 \\
\hline \multirow[t]{2}{*}{ pAtS18 } & $\underline{X G 5 A-5}$ & 3 & 19 & 19 & 0 & 100 \\
\hline & $X G 2 C-7$ & 2 & 10 & 0 & 10 & 0 \\
\hline \multirow[t]{2}{*}{ pCaMV35S } & $\underline{\text { SG15A-2 }}$ & 2 & 11 & 11 & 0 & 100 \\
\hline & SG19b-5 & 2 & 10 & 0 & 10 & 0 \\
\hline Control vector & NEG15B-5 & 3 & 18 & 0 & 18 & 0 \\
\hline
\end{tabular}

Lines selected for onward work based on stable expression patterns are underlined

GUS+, number of transgenic roots where a GUS signal was detected. GUS-, number of transgenic roots with no detectable blue staining. \%GUS+, percentage of GUS+ roots

Cross sections revealed that despite this cortical activity, pAtS13:GUS was clearly most strongly expressed in phloem cells of the nodule vascular bundles (Fig. 4o, p). Root phloem expression of this promoter was detectable throughout nodulated roots (Additional file 1: Fig. S6i).

Nodules of roots expressing pAtS18:GUS showed GUS staining restricted to xylem elements of nodule vascular bundles (Fig. $4 \mathrm{q}-\mathrm{t}$ ). This activity was traceable also in young nodules once vascular bundles began to differentiate (Fig. 4q). Cross sections revealed that only a subset of xylem elements were affected, but reliable quantification was impaired by the difficulty of visually tracing the highly specific GUS signal through lenticel cell layers from the outside, as well as the fact that cross sections only grant a spatially limited insight. pAtS18:GUS activity in root xylem elements resembled that observed in uninoculated roots (Additional file 1: Fig. S6e).

\section{Degree of cell type enrichment}

Cell type enrichment was especially evident upon analysis of thicker preparations from hand or vibratome sectioned roots (Additional file 1: Fig. S3). Such sections were used for analyzing larger numbers of roots but were less suitable for photography using a single focal plane. Three to five representative samples from two to three independent replicates were therefore embedded for the preparation of semithin sections and used for visual documentation. This revealed that with the exception of the weakly active pAtS18 (proto- and metaxylem), none of the tested promoters seemed entirely limited in activity to the cell type of primary expression. While there usually was a pronounced enrichment of activity in one particular cell type, this was often accompanied by lower level expression activity in one or more other cell types (Figs. 1, 2, 4, Additional file 1: Fig. S1, Table 1). Some of the presented promoters, such as pAtRHS14 (epidermis and cortex), pAtE29 (endodermis and pericycle) or $p A t S 32$ (phloem and pericycle) will thus be of interest primarily in approaches targeting combinations of adjacent cell types.

Unspecific processing of the GUS substrate X-Gluc (5-bromo-4-chloro-3-indolyl glucuronide) by endogenous enzymes is an unlikely cause of background staining, as control roots transformed with a vector lacking the promoter:GUS expression cassette showed no blue signal (Additional file 1: Fig. S1.4g-l; Tables 2,3, Additional file 2: Table S1).

Signal leakage from the cells of GUS expression to surrounding cells may have contributed to its presence in cells neighboring the cell type of primary activity. Fixing the transgenic roots in advance of applying X-Gluc, which to our experience significantly increased staining specificity while decreasing sensitivity, reduced the amount of GUS signal below the visual detection limit in all cases except the strong $p C a M V 35 S$ positive control. This reflects that all tested promoters were moderate in overall expression intensity, an important aspect that will benefit applications aiming to perform directed 


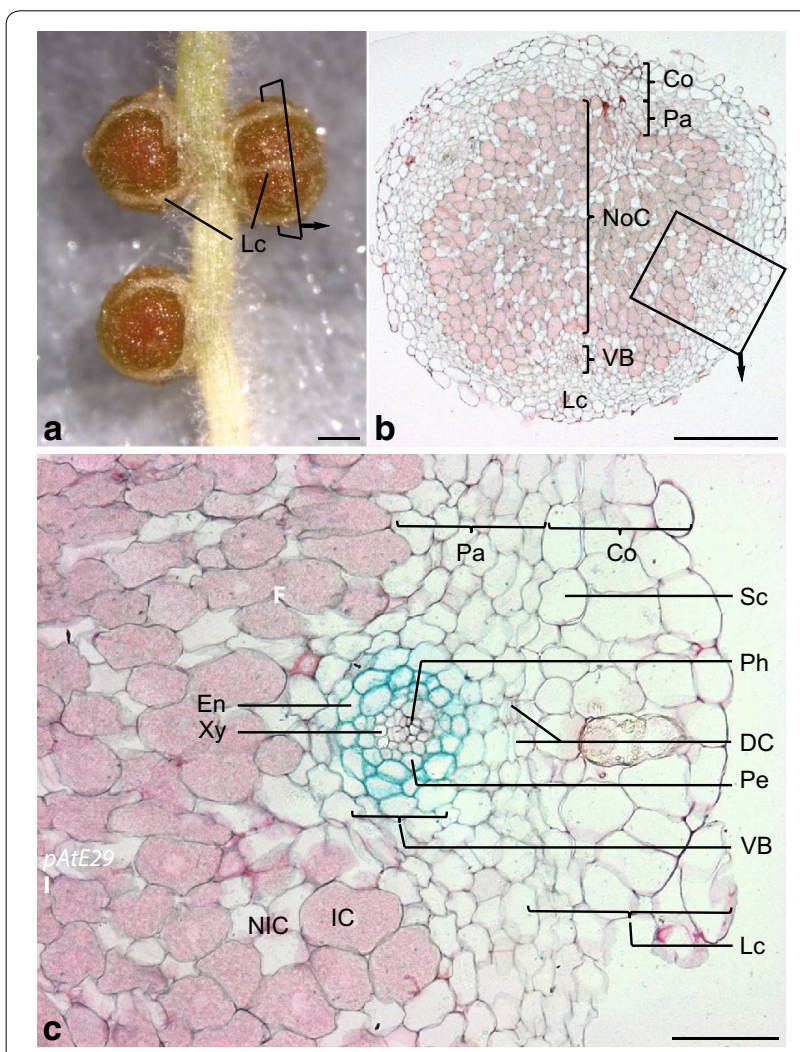

Fig. 3 Anatomy of L. japonicus nodules. a Mature nodules on a wild type plant, ecotype Gifu. Lenticels (LC) allowing for air exchange are apparent as white stripes on the nodule surface. The rectangle indicates the plane of a cross section as shown in (b). b Cross section through a wild type nodule. Cells of the nodule centre [57] infected with M. loti bacteria appear pink due to Ruthenium Red staining and co-exist with non-infected cells. The rectangle indicates an excerpt as shown in c. c Close-up of a nodule vascular bundle and lenticel and associated inner and outer nodule cell types. The excerpt is a reproduction of Fig. 4 and shows a section of a GUS-stained nodule expressing pAtS13:GUS with activity in the vascular endodermis (En) and pericycle (Pe). DC Dividing cells, $/ C$ infected cell, Pa nodule parenchyma, LC lenticel, NIC interstitial non-infected cell of the nodule centre, NoC nodule centre, VB vascular bundle, Co outer nodule cortex, Ph phloem cells, Sc sclereid cell layer surrounding the nodule, En vascular endodermis, Pe vascular pericycle, Xy xylem cells. Nomenclature follows Guinel [58], as well as the suggestion of van de Wiel et al. [59] to refer to the inner nodule cortex as nodule parenchyma. Cross sections are 7-8 $\mu \mathrm{m}$ microtome sections of resin (Kulzer Technovit 7100) embedded roots stained with $0.1 \%$ Ruthenium Red. Scale bars a $1 \mathrm{~mm}$; b $50 \mu \mathrm{m} ; \mathbf{c} 20 \mu \mathrm{m}$

expression of target genes in selected cell types and testing for biological effects while avoiding artifacts related to overexpression.

For a subset of promoters including pLeExt1, pAtS5, $p A t S 13, p A t S 32$ and $p A t E 30$ from the list of those showing detectable activity using GUS fusions, we have prepared additional marker fusion constructs using the triple yellow fluorescent protein (tYFP) locating to the cell cytoplasm. However, only the strong $p$ CaMV35S promoter gave a reproducible, screenable signal above auto-fluorescence of L. japonicus roots. Based on previous evidence indicating a higher sensitivity of the GUS reporter system compared to cytoplasm localized green fluorescent protein [46] we thus turned to promoter:GUS fusions for our further analyses.

In contrast, using transcriptional and/or translational fusions to GFP localized to the endoplasmatic reticulum, Lee et al. could detect expression of $79 \%$ of the 61 cell type enriched promoters selected based on microarray expression data obtained from root cell type specific cell populations $[6,10]$ in the native Arabidopsis. Where the expression pattern detected with fluorescent markers resembled that established via transcriptome analysis, fluorescence was seen only in the most strongly represented cell types [6, 10]. Similarly, our results suggest that while the tested promoters may indeed show broader expression ranges in L. japonicus compared to the endogenous Arabidopsis, higher detection sensitivity using the GUS reporter system may reveal low levels of expression present in other than the dominant cell type(s). In line with this, for the xylem enriched promoter $p A t S 18$, where activity was exclusively seen in xylem cells in $L$. japonicus roots based on GUS signal analysis, ca. $96 \%$ of the transcripts detected in the microarray [10] stemmed from the xylem-fraction.

\section{Conclusions and perspectives}

We present a promoter toolbox for cell type enriched expression analysis in roots and nodules of the model legume L. japonicus, which we expect to significantly contribute to our understanding of nodulation symbiosis as well as root development in legumes. Beyond assisting in the analysis of individual genes' function in L. japonicus roots and nodules, the promoters presented in this study can provide a stepping-stone for global translatome analysis of L. japonicus roots undergoing initial stages of symbiosis. Such analyses will significantly improve the resolution of our current understanding of root symbiosis from the organ- to the cell type level.

\section{Methods \\ Biological material}

Cloning works made use of E. coli strains TOP10 or DB3.1. Agrobacterium tumefaciens AGL1 [47] was used for whole plant transformation and Agrobacterium rhizogenes AR1193 [48] for transgenic root generation. Mesorhizobium loti MAFF 303099 expressing DsRED [49] for L. japonicus infection experiments. Promoter expression analysis was performed in transgenic roots of L. japonicus ecotypes MG20 [50] and Gifu B-129 [51]. 
Table 3 Promoter:GUS activity in 14 dpi nodules

\begin{tabular}{|c|c|c|c|c|}
\hline Promoter & Line name & Total plant \# & Mature nodules (GUS+/total) & Immature nodules (GUS+/total) \\
\hline pleExt 1 & LIG29-2 & 33 & $0 / 134$ & $0 / 63$ \\
\hline pAtCortex & CoG11-6 & 16 & $62 / 62$ & $48 / 48$ \\
\hline pAtE29 & $29 G 4 b-5$ & 19 & $69 / 69$ & $24^{a} / 25$ \\
\hline pAtS13 & $13 G 26 b-28$ & 25 & $131 / 131$ & $12^{b} / 30$ \\
\hline pAtS18 & $X G 5 A-5$ & 32 & $c / 127$ & $c / 57$ \\
\hline Control vector & NEG15B-5 & 34 & $0 / 134$ & $0 / 49$ \\
\hline
\end{tabular}

a Staining in immature nodules of this line followed the extent of the vascular bundles. Where these had not developed staining was limited to the nodule bases

b Immature nodules were unstained in early stages but showed increasing degrees of GUS staining towards reaching maturity

c Staining was difficult to trace reliably based on stereolupe inspection, so no number is provided here

GUS+, number of nodules where a GUS signal was detected. Nodules were harvested at 14 days post inoculation with Mesorhizobium loti (dpi)

\section{Promoter isolation}

Promoter candidates were selected based on published expression patterns in plant roots and amplified for sequence cloning and verification from genomic DNA of A. thaliana var. Col-0 or from plasmid templates ( $p A t$ SUC2, pLeExt1). A pENTR/D-TOPO (Invitrogen, Life Technologies) based construct containing pE30 [6] was kindly provided by P. Benfey (Duke University, Durham, USA) and used for recombination into expression vectors.

\section{Expression construct generation}

To analyze their expression patterns in L. japonicus roots, promoter fragments were inserted before an introncontaining $\beta$-glucuronidase (GUS) coding sequence [52] followed by a CaMV35S terminator using a Gateway (Invitrogen, Life Technologies)-compatible derivative of a pIV10 [48] integration plasmid (selection: $100 \mathrm{mg} / \mathrm{l}$ ampicillin and $100 \mathrm{mg} / \mathrm{l}$ spectinomycin). Upon transformation into appropriate $A$. rhizogenes the latter recombines into the transfer-DNA of the agrobacterial root inducing plasmid [48]. Gateway recombination reactions were done following manufacturers' instructions (Invitrogen, Life Technologies).

Constructs for stable transformation are based on a pGreenII0029 (selection: kanamycin $50 \mathrm{mg} / \mathrm{l}$ ) binary plasmid equipped with a Gateway (Invitrogen, Life Technologies) destination cassette followed by GUS coding and CaMV35S terminator sequences as used in the pIV10 construct employed in transgenic root generation.

Fragments for cloning were amplified using Phusion High-Fidelity DNA Polymerase (Fermentas, Life Technologies) following manufacturers' instructions. All intermediate and final constructs were confirmed by Sanger sequencing. Primers used for promoter fragment amplification and cloning are listed in Additional file 2: Table S2.

\section{Plant growth and transformation}

Lotus japonicus seeds were scarified in sulphuric acid for up to 20 min depending on age and subsequently surface sterilized in $0.5-1 \%$ sodium hypochlorite solution for $20 \mathrm{~min}$. Seeds were then imbibed at $4{ }^{\circ} \mathrm{C}$ overnight and grown in a $16 \mathrm{~h}$ light $/ 8 \mathrm{~h}$ dark regime at $21 / 16^{\circ} \mathrm{C}$, respectively. Transgenic roots were generated as previously described [31]. Composite plants were grown on $12 \times 12 \mathrm{~cm}$ square cultivation dishes on wedged $0.5 \times$ strength Gamborg B5 medium (Duchefa Biochemistry) supplemented with $1 \%$ Agar Noble (SigmaAldrich) for 6 weeks. They were then transferred to magenta growth containers (Sigma-Aldrich) with a 4:1 mix of Leca clay granules (Optiroc) and Vermiculite in $60 \mathrm{ml}$ of $0.25 \%$ Broughton and Dilworth medium [53] supplemented with $1 \mathrm{mM} \mathrm{KNO}$ (B\&D). After 10 days, plants were either mock treated with $20 \mathrm{ml} \mathrm{1/4}$ strength $\mathrm{B} \& \mathrm{D}$ medium or inoculated with $20 \mathrm{ml}$ of an $M$. loti suspension in $1 / 4$ strength $B \& D$ at an optical density of 0.001 at $\lambda=600 \mathrm{~nm}$.

Whole plant transformation of L. japonicus Gifu seedlings was done using a modified version of an earlier published protocol [54]. Shoots emerging from calli were transferred to soil substrate for rooting at a length of three to four $\mathrm{cm}$ and kept under greenhouse conditions until the seeding stage. Plants were genotyped for transgene presence, and seeds were collected from positively scoring plants for the isolation of lines homozygous for one transgene insertion. Seeds of three to four homozygous lines were collected and germinated as described above, then transferred directly to magenta growth containers. After 1 week of growth, plants were either mock treated with $20 \mathrm{ml} 1 / 4$ strength $B \& D$ medium or inoculated with $20 \mathrm{ml}$ of an $M$. loti suspension in $1 / 4$ strength B\&D at an optical density of 0.001 at $\lambda=600 \mathrm{~nm}$ and harvested 2 weeks after inoculation. Cultivation conditions were as described for composite plants. 

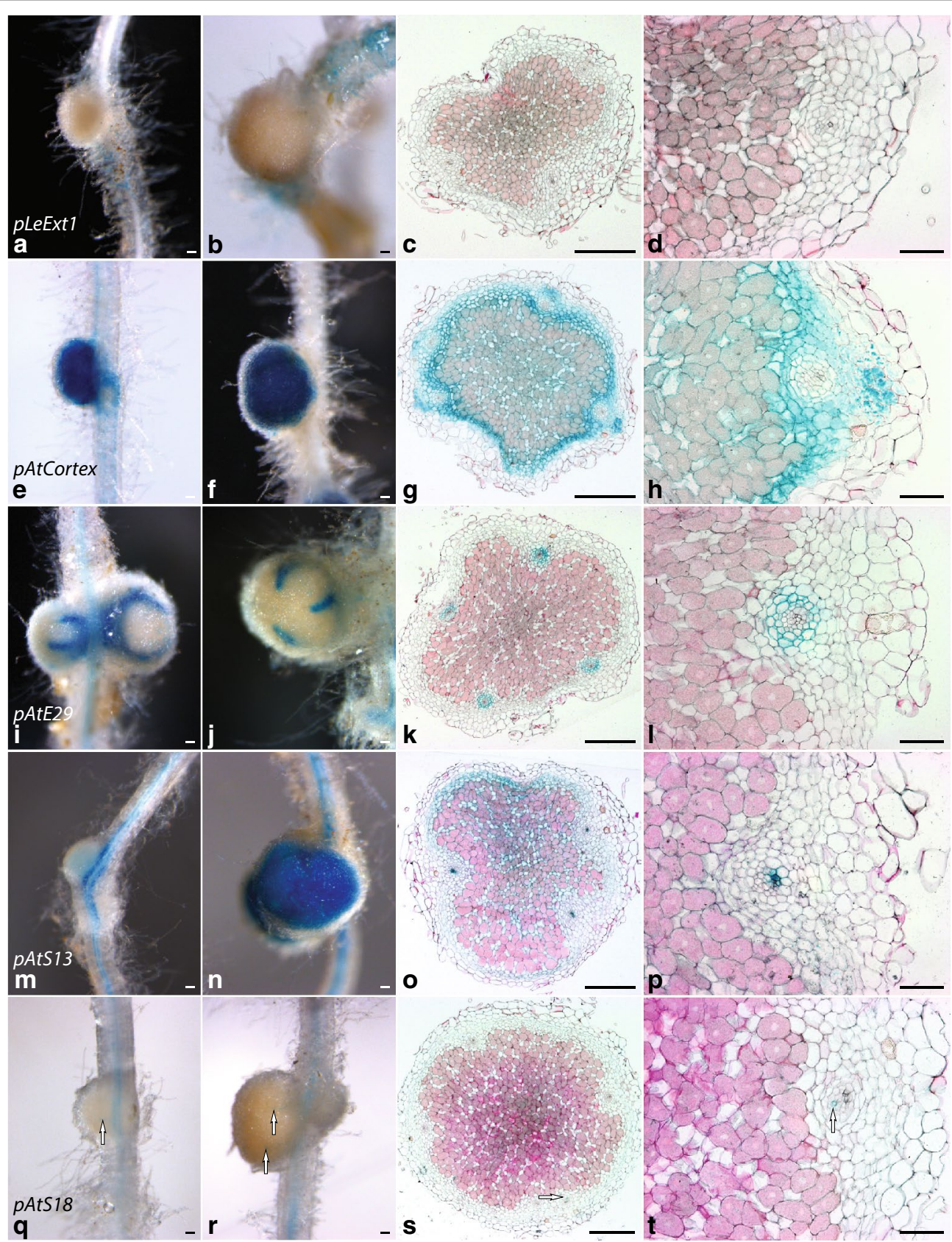

Fig. 4 Promoter activity as indicated by GUS staining in immature and mature nodules on transgenic plants expressing selected promoter:GUS constructs. Transgenes are a-d pLeExt1:GUS (line LIG29-2); e-h pAtCortex:GUS (line CoG11-6); i-I pAtE29:GUS (line 29G4b-5); m-p pAtS13:GUS (line 13G26b-28) and q-t pAtS18:GUS (line XG5A-5). Plants were inoculated with M. loti at 1 week of age and harvested at 2 weeks post germination. Representative GUS stained immature $(\mathbf{a}, \mathbf{e}, \mathbf{i}, \mathbf{m}, \mathbf{q})$ and mature $(\mathbf{b}-\mathbf{d}, \mathbf{f}-\mathbf{h}, \mathbf{j}-\mathbf{I}, \mathbf{n}-\mathbf{p}, \mathbf{r}-\mathbf{t})$ nodules. Entire mounts $(\mathbf{a}-\mathbf{b}, \mathbf{e}-\mathbf{f}, \mathbf{i}-\mathbf{j}, \mathbf{m}-\mathbf{n}, \mathbf{q}-\mathbf{r})$ or cross sections ( $\mathbf{c}-\mathbf{d}, \mathbf{g}-\mathbf{h}, \mathbf{k}-\mathbf{I}, \mathbf{0}-\mathbf{p}, \mathbf{s}-\mathbf{t})$ are shown. Cross sections are $7-8 \mu \mathrm{m}$ microtome sections of resin (Kulzer Technovit 7100) embedded roots stained with $0.1 \%$ Ruthenium Red. Scale bars d, h, I, p, t $20 \mu \mathrm{m}$, else $50 \mu \mathrm{m}$

\section{Identification of transgene insertion sites in transgenic plants}

To isolate lines containing a minimal number of transgene insertions and to facilitate the identification of integration sites, we have adapted
Sequence-Specific Amplification Polymorphism (SSAP) analysis in the L. japonicus background [55] for pGreenII0029 transfer-DNA. Lines containing one or two transgene insertion sites were considered for onward analysis. 


\section{GUS staining and fixation}

GUS staining was done as described by Vitha et al. [56] with few modifications. Briefly, roots were harvested into ice-cold phosphate buffer $\left(50 \mathrm{mM} \mathrm{NaH} \mathrm{PO}_{4}, 50 \mathrm{mM}\right.$ $\mathrm{Na}_{2} \mathrm{HPO}_{4}, \mathrm{pH}$ 7.0). Phosphate buffer was then exchanged for X-Gluc substrate buffer $[0.5 \mathrm{mg} / \mathrm{ml} \mathrm{X-Gluc} \mathrm{dissolved}$ in DMSO, $50 \mathrm{mM}$ phosphate buffer, $1 \mathrm{mM} \mathrm{K}_{4}\left(\mathrm{Fe}(\mathrm{CN})_{6}\right)$, $1 \mathrm{mM} \mathrm{K}\left(\mathrm{Fe}(\mathrm{CN})_{6}\right), 0.05 \%$ Triton X-100]. Roots were vacuum infiltrated for $10 \mathrm{~min}$ and incubated in staining buffer for $12 \mathrm{~h}$ at $37^{\circ} \mathrm{C}$.

For direct inspection or embedding in agarose, roots were fixed by vacuum infiltration for $10 \mathrm{~min}$ at room temperature, followed by $30 \mathrm{~min}$ incubation at $4{ }^{\circ} \mathrm{C}$ in a solution of $4 \%$ glutaraldehyde in $50 \mathrm{mM}$ phosphate buffer, $\mathrm{pH} 7$.

For semithin sections, a representative subset of stained root and nodule samples were fixed by vacuum infiltration in a solution of $4 \%$ paraformaldehyde and $1 \%$ glutaraldehyde in $100 \mathrm{mM}$ phosphate buffer (pH 7.2) for $20 \mathrm{~min}$, incubated at $4{ }^{\circ} \mathrm{C}$ over night while shaking, then dehydrated in serial dilutions of ethanol in water $(15,30$, 45 and $60 \%$ ) for $30 \mathrm{~min}$ each and stored in $70 \%$ ethanol. Roots were then embedded in Kulzer Technovit 7100 resin (Emgrid Australia) following the manufacturers' instructions.

\section{Microscopic analysis}

GUS stained, fixed roots and nodules were viewed and documented directly using a Leica M165FC stereomicroscope and Leica DFC 310 FX camera system. Entire roots were analyzed longitudinally, and root zones responsive to rhizobial infection identified by the presence of immature, developing root hairs (differentiation zone) were cross-sectioned to visualize expression patterns in inner root cell types. For analysis of cross sections, roots or nodules were embedded in $3 \%$ agarose and sectioned at 60-80 $\gamma \mathrm{m}$ thickness using a vibratome (Leica VT 1000 $\mathrm{S}$, Leica). Vibratome sections of were used for screening larger numbers of roots, and 3-5 representative samples were used to generate semithin sections. Semithin sections $(7-8 \gamma \mathrm{m})$ of resin embedded samples were prepared using a Leica RM2045 microtome and stained with $0.1 \%$ Ruthenium Red (Sigma-Aldrich) in water. Cross sections were analyzed using an Axioplan 2 microscope (Zeiss), and pictures were taken with an AxioCam color camera from the same supplier.

\section{Additional files}

Additional file 1: Figure S1. Activity patterns of promoter candidates showing epidermis enriched (Figure S1.1), general cortex- or endodermis enriched (Figure S1.2), pericycle and phloem enriched (Figure S1.3) or xylem specific (Figure S1.4) expression in L. japonicus roots. Figure S1.4g-I show roots expressing a control vector devoid of a promoter:GUS expression cassette. Agrobacterium rhizogenes induced transgenic roots were harvested three days after mock treatment (mock) with medium or inoculation with M. Ioti bacteria. Representative GUS stained root tips (a,d,g,j, $\mathbf{m}, \mathbf{p}$ entire root mounts) and responsive zone fragments (b,e,h,k,n,q entire root mounts; $\mathbf{c}, \mathbf{f}, \mathbf{i}, \mathbf{l}, \mathbf{l}, \mathbf{r}$ cross sections) are shown. Cross sections are 7-8 $\mu \mathrm{m}$ microtome sections of resin (Kulzer Technovit 7100) embedded roots stained with $0.1 \%$ Ruthenium Red. Scale bars 50 m. Figure S2. Root tip associated GUS signal varied with root hair emergence patterns in pLeExt 1:GUS expressing roots. Where root hairs developed near the root tip, epidermal cells showed GUS activity in a distinct ring of blue encircling the root tip. GUS stained and fixed tips of Agrobacterium rhizogenes induced transgenic roots harvested $\mathbf{a}$ three days after mock treatment (mock) with medium or $\mathbf{b}$ inoculation with M. loti bacteria are shown. Scale bars $50 \mu \mathrm{m}$. Figure S3. Vibratome sections of pAtCortex:GUS expressing roots show strong enrichment of GUS signal in cortical cells. a-b $60-80 \mu \mathrm{m}$ sections of the responsive zone of pAtCortex:GUS expressing L. japonicus roots. Roots were stained, fixed and embedded in $2.4 \%$ agarose prior to sectioning. Scale bars $50 \mu \mathrm{m}$. Figure S4. pAtSUC2 activity pattern in transgenic L. japonicus roots. a-b roots shielded from light access show no GUS staining. c-d chloroplastcontaining roots exposed to light show GUS signal in phloem cells. Arrows indicate GUS signal in chloroplast containing roots. Representative longitudinal views of GUS stained whole root mounts are shown. e crosssection of resin (Kulzer Technovit 7100) embedded root responsive zone stained with $0.1 \%$ Ruthenium Red. Black arrows point to phloem poles, white arrows to pericycle cells showing GUS signal. The respective root had been exposed to light during development. Scale bars a-d $100 \mu \mathrm{m}$, e 50 um. Figure S5. Promoter activity distribution across developmental zones of representative roots stably expressing promoter:GUS constructs. Transgenes are a $p$ LeExt1:GUS (line LIG29-2); b pAtCortex:GUS (line CoG1 16); c PAtE29:GUS (line 29G4b-5); d pAtS13:GUS (line 13G26b-28) and e pAtS18:GUS (line XG5A-5). Transgenic plants were uninoculated and harvested as well as GUS stained at three weeks post germination. Scale bars $1 \mathrm{~mm}$. Figure S6. Promoter activity distribution across developmental zones of representative nodulated roots stably expressing promoter:GUS constructs. Transgenes are a pLeExt1:GUS (line LIG29-2); b pAtCortex:GUS (line CoG11-6); c pAtE29:GUS (line 29G4b-5); d pAtS13:GUS (line 13G26b28) and e pAtS18:GUS (line XG5A-5). Transgenic plants were harvested and GUS stained at two weeks after inoculation with M. loti. Scale bars $1 \mathrm{~mm}$.

Additional file 2: Table S1. L. japonicus roots showing GUS staining when transformed with the tested promoter:GUS constructs. Table S2. Oligonucleotide primers used for amplification and cloning of promoter fragments presented in this manuscript.

\section{Authors' contributions}

SG performed experiments with support by ZY, KM, and AJ; JS provided advice and edited the manuscript; SG and KM planned experiments and KM wrote the manuscript. All authors read and approved the final manuscript. 


\section{Acknowledgements}

We are grateful to P. Benfey (Duke University, Durham, USA) for providing pENTR/D-TOPO plasmids containing pAtE28, pAtE30, pAtS17 and pAtS21, M. Bucher (University of Cologne, Germany) for providing the pLeExtl and N. Sauer and R. Stadler (Friedrich-Alexander-Universität Erlangen-Nürnberg, Germany) for providing the pAtSUC2 promoter fragments used in this manuscript. We thank Daniela Tsikou for help with preparing plants, and Dörte Meyer and Linards Klavins for excellent technical assistance. This work was supported by the Danish National Research Foundation Grant no. DNRF79 and the ERC Advanced Grant 268523.

\section{Competing interests}

The authors declare that they have no competing interests.

\section{Statement}

The experiments were performed in facilities classified for recombinant work with bacteria and plants and in accordance with Danish regulations for genetically modified organisms and good laboratory practice.

Received: 24 July 2015 Accepted: 5 January 2016

Published online: 22 January 2016

\section{References}

1. Jones B, Ljung K. Subterranean space exploration: the development of root system architecture. Curr Opin Plant Biol. 2012;15:97-102.

2. Baetz U, Martinoia E. Root exudates: the hidden part of plant defense. Trends Plant Sci. 2014;19:90-8.

3. De Coninck B, Timmermans P, Vos C, Cammue BP, Kazan K. What lies beneath: belowground defense strategies in plants. Trends Plant Sci. 2015;20:91-101.

4. Dinneny JR, Long TA, Wang JY, Jung JW, Mace D, Pointer S, et al. Cell identity mediates the response of Arabidopsis roots to abiotic stress. Science. 2008;320:942-5.

5. Ivanov VB, Dubrovsky JG. Longitudinal zonation pattern in plant roots: conflicts and solutions. Trends Plant Sci. 2013:18:237-43.

6. Lee JY, Colinas J, Wang JY, Mace D, Ohler U, Benfey PN. Transcriptional and posttranscriptional regulation of transcription factor expression in Arabidopsis roots. Proc Natl Acad Sci U S A. 2006;103:6055-60.

7. Tsukagoshi H, Busch W, Benfey PN. Transcriptional regulation of ROS controls transition from proliferation to differentiation in the root. Cell. 2010;143:606-16.

8. Lee MM, Schiefelbein J. WEREWOLF, a MYB-related protein in Arabidopsis, is a position-dependent regulator of epidermal cell patterning. Cell. 1999:99:473-83.

9. Galinha C, Hofhuis H, Luijten M, Willemsen V, Blilou I, Heidstra R, et al. PLETHORA proteins as dose-dependent master regulators of Arabidopsis root development. Nature. 2007;449:1053-7.

10. Birnbaum K, Shasha DE, Wang JY, Jung JW, Lambert GM, Galbraith DW, et al. A gene expression map of the Arabidopsis root. Science. 2003;302:1956-60.

11. Dello loio R, Linhares FS, Scacchi E, Casamitjana-Martinez E, Heidstra R, Costantino $P$, et al. Cytokinins determine Arabidopsis root-meristem size by controlling cell differentiation. Curr Biol. 2007;17:678-82.

12. Mahonen AP, Bishopp A, Higuchi M, Nieminen KM, Kinoshita K, Tormakangas K, et al. Cytokinin signaling and its inhibitor AHP6 regulate cell fate during vascular development. Science. 2006;311:94-8.

13. Mahonen AP, ten Tusscher K, Siligato R, Smetana O, Diaz-Trivino S, Salojarvi J, et al. PLETHORA gradient formation mechanism separates auxin responses. Nature. 2014;515:125-9.

14. Petersson SV, Johansson Al, Kowalczyk M, Makoveychuk A, Wang JY, Moritz T, et al. An auxin gradient and maximum in the Arabidopsis root apex shown by high-resolution cell-specific analysis of IAA distribution and synthesis. Plant Cell. 2009;21:1659-68.

15. Nakajima K, Sena G, Nawy T, Benfey PN. Intercellular movement of the putative transcription factor SHR in root patterning. Nature. 2001:413:307-11.

16. Rim Y, Huang L, Chu H, Han X, Cho WK, Jeon CO, et al. Analysis of Arabidopsis transcription factor families revealed extensive capacity for cell-to-cell movement as well as discrete trafficking patterns. Mol Cells. 2011;32:519-26.

17. Vaten A, Dettmer J, Wu S, Stierhof YD, Miyashima S, Yadav SR, et al. Callose biosynthesis regulates symplastic trafficking during root development. Dev Cell. 2011;21:1144-55.

18. Carlsbecker A, Lee JY, Roberts CJ, Dettmer J, Lehesranta S, Zhou J, et al. Cell signalling by microRNA165/6 directs gene dose-dependent root cell fate. Nature. 2010;465:316-21.

19. Høgslund N, Radutoiu S, Krusell L, Voroshilova V, Hannah MA, Goffard $\mathrm{N}$, et al. Dissection of symbiosis and organ development by integrated transcriptome analysis of Lotus japonicus mutant and wild-type plants. PLoS One. 2009;4:e6556.

20. Oldroyd GE. Speak, friend, and enter: signalling systems that promote beneficial symbiotic associations in plants. Nat Rev Microbiol. 2013;11:252-63.

21. Madsen LH, Tirichine L, Jurkiewicz A, Sullivan JT, Heckmann AB, Bek AS, et al. The molecular network governing nodule organogenesis and infection in the model legume Lotus japonicus. Nat Commun. 2010;1:10.

22. Held M, Hou H, Miri M, Huynh C, Ross L, Hossain MS, et al. Lotus japonicus cytokinin receptors work partially redundantly to mediate nodule formation. Plant Cell. 2014;26:678-94.

23. Murray JD, Karas BJ, Sato S, Tabata S, Amyot L, Szczyglowski K. A cytokinin perception mutant colonized by Rhizobium in the absence of nodule organogenesis. Science. 2007:315:101-4.

24. Oldroyd GE, Downie JA. Coordinating nodule morphogenesis with rhizobial infection in legumes. Annu Rev Plant Biol. 2008;59:519-46.

25. Gaude N, Schulze WX, Franken P, Krajinski F. Cell type-specific protein and transcription profiles implicate periarbuscular membrane synthesis as an important carbon sink in the mycorrhizal symbiosis. Plant Signal Behav. 2012;7:461-4.

26. Giovannetti M, Balestrini R, Volpe V, Guether M, Straub D, Costa A, et al. Two putative-aquaporin genes are differentially expressed during arbuscular mycorrhizal symbiosis in Lotus japonicus. BMC Plant Biol. 2012;12:186.

27. Hogekamp C, Arndt D, Pereira PA, Becker JD, Hohnjec N, Kuster H. Laser microdissection unravels cell-type-specific transcription in arbuscular mycorrhizal roots, including CAAT-box transcription factor gene expression correlating with fungal contact and spread. Plant Physiol. 2011;157:2023-43.

28. Hogekamp C, Kuster H. A roadmap of cell-type specific gene expression during sequential stages of the arbuscular mycorrhiza symbiosis. BMC Genom. 2013:14:306.

29. Limpens E, Moling S, Hooiveld G, Pereira PA, Bisseling T, Becker JD, et al. Cell- and tissue-specific transcriptome analyses of Medicago truncatula root nodules. PLoS One. 2013;8:e64377.

30. Roux B, Rodde N, Jardinaud MF, Timmers T, Sauviac L, Cottret L, et al. An integrated analysis of plant and bacterial gene expression in symbiotic root nodules using laser-capture microdissection coupled to RNA sequencing. Plant J. 2014;77:817-37.

31. Hansen J, Jørgensen J-E, Stougaard J, Marcker K. Hairy roots-a short cut to transgenic root nodules. Plant Cell Rep. 1998;8:12-5.

32. Bucher M, Brunner S, Zimmermann P, Zardi Gl, Amrhein N, Willmitzer L, et al. The expression of an extensin-like protein correlates with cellular tip growth in tomato. Plant Physiol. 2002;128:911-23.

33. Mirabella R, Franken C, van der Krogt GN, Bisseling T, Geurts R. Use of the fluorescent timer DsRED-E5 as reporter to monitor dynamics of gene activity in plants. Plant Physiol. 2004;135:1879-87.

34. Hayashi T, Shimoda Y, Sato S, Tabata S, Imaizumi-Anraku H, Hayashi M. Rhizobial infection does not require cortical expression of upstream common symbiosis genes responsible for the induction of $\mathrm{Ca}(2+)$ spiking. Plant J. 2014;77:146-59.

35. Won SK, Lee YJ, Lee HY, Heo YK, Cho M, Cho HT. Cis-element- and transcriptome-based screening of root hair-specific genes and their functional characterization in Arabidopsis. Plant Physiol. 2009:150:1459-73.

36. Ron M, Kajala K, Pauluzzi G, Wang D, Reynoso MA, Zumstein K, et al. Hairy root transformation using Agrobacterium rhizogenes as a tool for exploring cell type-specific gene expression and function using tomato as a model. Plant Physiol. 2014;166:455-69.

37. Stadler R, Lauterbach C, Sauer N. Cell-to-cell movement of green fluorescent protein reveals post-phloem transport in the outer integument and 
identifies symplastic domains in Arabidopsis seeds and embryos. Plant Physiol. 2005;139:701-12.

38. Kelly SJ, Muszynski A, Kawaharada Y, Hubber AM, Sullivan JT, Sandal N, et al. Conditional requirement for exopolysaccharide in the Mesorhizobium-Lotus symbiosis. Mol Plant Microbe Interact. 2013;26:319-29.

39. Lee KH, Larue TA. Ethylene as a possible mediator of light- and nitrateinduced inhibition of nodulation of Pisum sativum L. cv Sparkle. Plant Physiol. 1992;100:1334-8.

40. Chandran D, Reinders A, Ward JM. Substrate specificity of the Arabidopsis thaliana sucrose transporter AtSUC2. J Biol Chem. 2003;278:44320-5.

41. Gottwald JR, Krysan PJ, Young JC, Evert RF, Sussman MR. Genetic evidence for the in planta role of phloem-specific plasma membrane sucrose transporters. Proc Natl Acad Sci USA. 2000;97:13979-84.

42. Skirycz A, Reichelt M, Burow M, Birkemeyer C, Rolcik J, Kopka J, et al. DOF transcription factor AtDof1.1 (OBP2) is part of a regulatory network controlling glucosinolate biosynthesis in Arabidopsis. Plant J. 2006;47:10-24.

43. Ramirez V, Agorio A, Coego A, Garcia-Andrade J, Hernandez MJ, Balaguer $B$, et al. MYB46 modulates disease susceptibility to Botrytis cinerea in Arabidopsis. Plant Physiol. 2011;155:1920-35.

44. Ramirez V, Garcia-Andrade J, Vera P. Enhanced disease resistance to Botrytis cinerea in myb46 Arabidopsis plants is associated to an early down-regulation of CesA genes. Plant Signal Behav. 2011;6:911-3.

45. Ascencio-lbanez JT, Sozzani R, Lee TJ, Chu TM, Wolfinger RD, Cella R, et al. Global analysis of Arabidopsis gene expression uncovers a complex array of changes impacting pathogen response and cell cycle during geminivirus infection. Plant Physiol. 2008;148:436-54.

46. Quaedvlieg NE, Schlaman HR, Admiraal PC, Wijting SE, Stougaard J, Spaink HP. Fusions between green fluorescent protein and beta-glucuronidase as sensitive and vital bifunctional reporters in plants. Plant Mol Biol. 1998;37:715-27.

47. Lazo GR, Stein PA, Ludwig RA. A DNA transformation-competent Arabidopsis genomic library in Agrobacterium. Biotechnology (N Y). 1991:9:963-7.

48. Stougaard J, Abildsten D, Marcker KA. The Agrobacterium rhizogenes pRi TL-DNA segment as a gene vector system for transformation of plants. Mol Gen Genet. 1987;207:251-5.
49. Maekawa T, Maekawa-Yoshikawa M, Takeda N, Imaizumi-Anraku H, Murooka Y, Hayashi M. Gibberellin controls the nodulation signaling pathway in Lotus japonicus. Plant J. 2009;58:183-94.

50. Kawaguchi M. Lotus japonicus 'Miyakojima' MG-20: an early-flowering accession suitable for indoor handling. J Plant Res. 2000;113:507-9.

51. Handberg K, Stougaard J. Lotus japonicus, an autogamous, diploid legume species for classical and molecular genetics. Plant J. 1992;2:487-96.

52. Vancanneyt G, Schmidt R, O'Connor-Sanchez A, Willmitzer L, RochaSosa M. Construction of an intron-containing marker gene: splicing of the intron in transgenic plants and its use in monitoring early events in Agrobacterium-mediated plant transformation. Mol Gen Genet. 1990;220:245-50.

53. Broughton WJ, Dilworth MJ. Control of leghaemoglobin synthesis in snake beans. Biochem J. 1971;125:1075-80.

54. Thykaer T, Schauser L, Danielsen D, Finneman J, Stougaard J. Transgenic plants: Agrobacterium-mediated transformation of the diploid legume Lotus japonicus. Cell biology: a laboratory handbook. New York: Academic Press; 1998.

55. Urbanski DF, Malolepszy A, Stougaard J, Andersen SU. High-throughput and targeted genotyping of Lotus japonicus LORE1 insertion mutants. Methods Mol Biol. 2013;1069:119-46.

56. Vitha S, Benes K, Phillips JP, Gartland KM. Histochemical GUS analysis. Methods Mol Biol. 1995;44:185-93.

57. Pucciariello C, Innocenti G, Van de Velde W, Lambert A, Hopkins J, Clement $\mathrm{M}$, et al. (Homo)glutathione depletion modulates host gene expression during the symbiotic interaction between Medicago truncatula and Sinorhizobium meliloti. Plant Physiol. 2009;151:1186-96.

58. Guinel FC. Getting around the legume nodule: I. The structure of the peripheral zone in four nodule types. Botany. 2009;87:1117-38.

59. van de Wiel C, Scheres B, Franssen H, Lierop M-J, van Lammeren A, Van Kammen A, et al. The early nodulin transcript ENOD2 is located in the nodule parenchyma (inner cortex) of pea and soybean root nodules. EMBO J. 1990;9:1-7.

\section{Submit your next manuscript to BioMed Central and we will help you at every step:}

- We accept pre-submission inquiries

- Our selector tool helps you to find the most relevant journal

- We provide round the clock customer support

- Convenient online submission

- Thorough peer review

- Inclusion in PubMed and all major indexing services

- Maximum visibility for your research

Submit your manuscript at www.biomedcentral.com/submit
() Biomed Central 